\title{
Transformación y lucha de clases: el concepto de práctica en la filosofía de Louis Althusser
}

\author{
Transformation and class struggle: the concept of practice in Louis Althusser's philosophy
}

\author{
Constanza Filloy*
}

\begin{abstract}
Resumen: Este trabajo se centra en el concepto de práctica en el pensamiento de Louis Althusser. Presentamos un análisis de las modificaciones que sufre el concepto en la producción teórica del autor durante la década de los sesenta y hasta mediados de los setenta. En este sentido, analizamos la definición del carácter transformador de las prácticas, así como impacto del concepto de 'Teoría de la práctica teórica' en concepto general de práctica. Delimitamos un el desplazamiento efectuado por el autor desde la escisión teoría y práctica hacia una multiplicidad de prácticas inscriptas en el todo social marxista. Posteriormente, presentamos las alteraciones en el concepto durante la década de los setenta a partir de la introducción de la lucha de clases y la definición la filosofía como un campo de batalla. Mostramos la relevancia del principio de la primacía de la práctica y del exterior no filosófico constituido por las múltiples prácticas en la determinación de una una posición materialista en filosofía.
\end{abstract}

Palabras Clave: lucha de clases, transformación, práctica, teoría, Althusser

\begin{abstract}
The following study is focused on the concept of practice in the philosophy of Louis Althusser. It analyses the modifications in concept in the theoretical production of the author during the sixties and the mid-seventies. The article explores the definition of the transforming nature of practices, as well as the impact of the concept of 'Theory of theoretical practice' in the general concept of practice. It establishes the abandonment of theory and practice as a couple towards the definition of multiple practices located in the Marxist social whole. Finally, the study presents the transformations in the concept of practice in the mid-seventies due to the importance of the concept of class struggle and the definition of philosophy as a battlefield. Finally, it shows the relevance of the principle of the primacy of practice and of the non-philosophical exterior formed by the multiple practices in the determination of a materialist position in philosophy.
\end{abstract}

Keywords: class struggle, transformation, practice, theory, Althusser

Recibido: 6 febrero 2019 Aceptado: 12 mayo 2019

\footnotetext{
* Argentina. Profesora de Filosofía egresada de la Facultad de Filosofía y Humanidades de la Universidad Nacional de Córdoba. Becaria del Centro de Investigaciones en la misma institución. Integrante del equipo de investigación "Lenguajes de la crítica política: relaciones de poder, lógicas del capital y formas de vida" en el Centro de Investigaciones y Estudios sobre Cultura y Sociedad (CIECS), CONICET. E-mail: csfilloy@gmail.com
} 


\section{Introducción}

Inaugurando una discusión que continúa resonando en numerosos debates teóricos y políticos en el seno de la tradición marxista, Marx establece en las Tesis sobre Feuerbach un llamado a la práctica. En su conjunto, el texto de Marx propone una reivindicación de la materialidad de las prácticas y de la dimensión activa o productiva de las mismas; poniendo en escena el problema de la transformación y su vínculo con la práctica. Este gesto se entiende en el marco de la disputa con el idealismo, representado fundamentalmente por Hegel, en donde la realización del absoluto en el Sujeto se encuentra prioritariamente en un plano "ideal", pero también en oposición al empirismo ingenuo de Feuerbach que impide, al igual que Hegel, abordar la materialidad en términos de producción o actividad. Seguimos a Étienne Balibar al afirmar que en las Tesis se encuentra la exigencia del abandono de todo teoricismo a través de la práctica. ${ }^{1}$ Es notable una recuperación del imperativo "a la práctica" en diversos proyectos teóricos y discusiones en el seno del marxismo a lo largo del siglo XX. Posiblemente, la filosofía de la praxis reúne las lecturas más referenciadas de las Tesis y del concepto de praxis en la tradición marxista. Al menos dos de sus representantes más importantes, Sartre y Gramsci, coinciden en que es necesario saldar el hiato entre la práctica y la teoría para restituir la capacidad transformadora del materialismo dialéctico. El diagnóstico de Sartre con respecto al movimiento comunista es el de una separación entre la práctica y la teoría, cuya resolución consiste en la introducción de mediaciones con lo 'concreto'. Por su parte, el filósofo italiano retoma los ejes trazados en las Tesis en su propia obra al considerar que teoría y práctica consisten en dos dimensiones escindidas cuya unión puede y debe perseguirse en la historia. Así, el llamado a la práctica se ha topado insistentemente con el problema de la transformación y de su vínculo con la teoría.

Este trabajo se centra en el concepto de práctica en el pensamiento de Louis Althusser. La obra del filósofo argelino ha despertado un renovado interés desde la difusión de sus textos póstumos a partir de la década de 1990 y de la publicación en 2014 y 2015 de dos escritos inéditos escritos en 1976: Ser marxista en filosofía ${ }^{2}$ y la Iniciación a la filosofía para no filósofos. ${ }^{3}$ Seguimos la lectura de Alain Badiou, según la cual el concepto de práctica constituye el más general de la lectura que realiza Althusser del materialismo dialéctico ${ }^{4}$ para exhibir el modo en el que el concepto se inscribe en el proyecto teórico del filósofo y el modo en el que se articula con la categoría de transformación que las Tesis sobre Fenerbach establece. Así, la hipótesis que guía esta investigación es que, en el pensamiento del filósofo francés, la práctica es definida como un proceso transformador a partir de un doble movimiento: la introducción de la categoría de producción como operación característica en las prácticas, por un lado, y la constitución de las distintas prácticas en el escenario de la lucha de clases, por el otro. La contribución que pretendemos realizar mantiene, entonces, un doble alcance: en primera instancia, pretendemos presentar el carácter singular que adquiere la formulación althusseriana de la articulación de la teoría y la práctica en su lectura de las Tesis sobre Feuerbach, tensionando cierta imagen de Althusser como un intelectual comprometido con un antihumanismo "abstracto". Por otro lado, este trabajo procura inscribirse en un proceso de actual renovación y rediscusión del pensamiento de $\mathrm{Althusser}^{5}$, incursionando en el modo en el que la

1 Étienne, Balibar, La filosofía de Marx, Buenos Aires, Ediciones Nueva visión, 2000, 19.

${ }^{2}$ Louis Althusser, Ser marxista en filosofia, Buenos Aires, Akal, 2015.

${ }^{3}$ Louis Althusser, Iniciación a la filosofía para no filósofos, Buenos Aires, Paidós 2014.

4 Cfr. Alain Badiou, "El (re)comienzo del materialismo dialéctico" en Materialismo histórico y materialismo dialéctico, México, Ediciones Pasado y Presente Siglo XXI, 1979, 23.

5 De Acuerdo a Francois Matheron - responsable de haber inventariado el Fondo Althuser- el campo de los estudios althusserianos se encuentra en conformación en el presente. Al respecto, puede consultarse: Francois Matheron, "Louis Althusser o la impureza del concepto" trad. Starcenbaum M. En Demarcaciones. No 1. Disponible en: 
transformación y la lucha de clases se inscriben en la práctica. Tanto la definición de la práctica como el conjunto de prácticas registradas y la jerarquía que ellas presentan es objeto de modificaciones a lo largo de la producción teórica del autor. G. M. Goshgarian — uno de los editores, traductores y comentadores de la obra de Althusser-indica en su prefacio a la edición de Ser marxista en Filosofía ${ }^{6}$, que no es hasta la Iniciación a la filosofía para no filósofos que el proyecto althusseriano elabora una concepción propiamente marxista de la relación entre la teoría y la práctica. En este sentido, su reciente publicación habilita nuevas líneas de lectura del tema de investigación planteado.

En la primera parte de este trabajo desarrollamos la definición de la práctica elaborada por Althusser en los textos clásicos escritos durante los sesenta: La revolución teórica de Marx $x^{7}$ y Para leer El capital $^{8}$. Para esto, reconstruimos en primera instancia la definición de un concepto central durante este periodo: la 'Teoría de la práctica teórica'. En este contexto, evaluamos su impacto en el carácter transformador del concepto general de práctica. Luego, remarcamos un primer desplazamiento de la inscripción 'teoricista' del problema a partir de la afirmación de la primacía de la práctica y de la consecuente inserción de la práctica en el todo social estructurado en Para Leer el Capital. A continuación, nos detenemos en el concepto de todo social marxista como todo jerarquizado para indicar el tipo de contradicción específica que soportan las prácticas: la sobredeterminación. En la segunda parte del trabajo, analizamos la reinscripción del concepto de práctica bajo el nombre de Lenin en una nueva práctica de la filosofía para finalmente mostrar la centralidad de la lucha de clases y del principio de la primacía de la práctica en las posiciones que marcan el campo filosófico: el idealismo y el materialismo. En este punto, la delimitación con las llamadas tesis 'teoricistas' no pretende exhibir las falencias de la argumentación de Althusser en sus textos clásicos, sino mostrar en qué medida la jerarquización de la práctica política y de la lucha de clases incide en el concepto general de práctica. ${ }^{9}$ Intentamos señalar en qué medida el concepto elude la solución recurrente en la filosofía de la praxis según la cual teoría y práctica consisten en dos ámbitos cuya escisión ha de resolverse, para proponer una práctica de la filosofía determinada por la lucha de clases y volcada hacia su exterior no filosófico.

\section{¿Teoricismo de la práctica? La práctica teórica}

Para comenzar, resulta esclarecedor explicitar cuál es la tarea que organiza el proyecto althusseriano en sus textos clásicos: defender la cientificidad del materialismo histórico de sus recepciones ideológicas y explicitar sus conceptos e implicancias filosóficas, desplegados bajo la filosofía marxista, es decir, el materialismo dialéctico. En este proyecto ocupa un lugar central la tesis según la cual la fundación de una nueva teoría de la historia y una nueva filosofía en Marx pone en acción un corte epistemológico que implica un cambio de terreno al interior de su obra. El concepto de ruptura epistemológica, recuperado por Althusser de Bachelard, supone una transformación en la obra de Marx que habilita el

https://revistademarcaciones.cl/francois-matheron-louis-althusser-o-la-pureza-impura-del-concepto/. $2014 . \quad$ El fondo Althusser reúne la bibliografía completa y el conjunto de textos póstumos del autor hallados desde 1991. Dichos trabajos residen en el IMEC (Instituto Memorias de la Edición Contemporánea). Con respecto a la edición de los textos póstumos del autor y sus respectivos períodos de publicación, puede revisarse: Éwanjé-Épée, Felix Boggio y G.M. Goshgarian, "Filosofía y revolución. Althusser sin teoricismo: entrevista con G.M. Goshgarian" en Décalages: Vol. 2: Iss. 1. 2016. Disponible en: https://scholar.oxy.edu/decalages/vol2/iss2/11.

${ }^{6}$ Louis Althusser, Ser marxista en filosofía, Buenos Aires, Akal, 2015, 8.

7 Louis Althusser, Althusser, La revolución teórica de Marx, México, Siglo XXI.

8 Louis Althusser, Para leer El Capital, México, Siglo XXI, 2015.

${ }^{9}$ Louis Althusser, op cit, 8. 
surgimiento de nuevas preguntas en una problemática nueva ${ }^{10}$ que concierne a dos disciplinas: el materialismo histórico o ciencia de la historia, y el materialismo dialéctico. ${ }^{11}$

En ese contexto, Althusser lleva adelante una profunda evaluación del sentido de la dialéctica en Marx y, más precisamente, de su diferencia con respecto a la dialéctica hegeliana. Esto lo lleva a ocupar buena parte de sus esfuerzos a determinar la especificidad de la dialéctica materialista, y a afirmar que el desarrollo filosófico del marxismo depende de esta tarea. ${ }^{12}$ La ruptura epistemológica captura lo esencial de la transformación de una concepción idealista de la dialéctica hacia una nueva problemática teórica en la obra de Marx en la cual la dialéctica es formulada en nuevos términos. El problema de la inversión de la dialéctica hegeliana en Marx es considerado a partir de la transformación de la naturaleza misma de la dialéctica. De este modo, Althusser insiste en que la dialéctica hegeliana no sufre una simple alteración en el 'orden de los términos' en su inversión: el "descubrimiento del núcleo racional” de la dialéctica que Marx realiza requiere de la elucidación de sus estructuras específicas ${ }^{13}$; que no repiten, invirtiéndolos, los motivos de la dialéctica hegeliana. Más precisamente, la transformación de la naturaleza de la dialéctica supone una evaluación de sus estructuras: contradicción, escisión, superación, negación, separación, etc.

Althusser introduce el concepto de práctica en la Revolución Teórica de Marx en las primeras líneas del artículo Sobre la Dialéctica Materialista (de la desigualdad de los orígenes), luego de una recuperación de la VIII Tesis de Feuerbach en donde se establece a la práctica como "solución racional al extravío de la teoría hacia el misticismo". ${ }^{14}$ Anuncia, de este modo, una lectura de las Tesis sobre Feuerbach en la que el misticismo al cual la teoría se expone encuentra un límite en el llamado a la práctica. La práctica consiste en un proceso de transformación de una materia prima en un producto a partir del trabajo:

Por práctica en general entenderemos todo proceso de transformación de una materia primera dada determinada en un producto determinado, transformación efectuada por un trabajo humano determinado, utilizando medios (de "producción”) determinados. En toda práctica así concebida el momento (o el elemento) determinante del proceso no es la materia prima ni el producto, sino la práctica en el sentido estricto: el momento mismo del trabajo de transformación, que pone en acción, dentro de una estructura específica, hombres, medios y un método técnico de utilización de los medios. ${ }^{15}$

Así, el proceso de transformación que la práctica define, debe ser entendido a partir de su efecto productivo. Alain Badiou ofrece una definición de la dialéctica materialista que resume de manera notable lo que señalamos aquí: la filosofía marxista o materialismo dialéctico presenta una "teoría formal de las rupturas" ${ }^{16}$. Si, como hemos anticipado, la práctica constituye el concepto más general del materialismo dialéctico, las prácticas singulares son definidas en función de una combinación específica de los términos involucrados en el proceso descrito. ${ }^{17}$

\footnotetext{
10 Con el concepto de ruptura epistemológica, Althusser forma parte de la tradición francesa que hizo de la ciencia y de la discontinuidad del conocimiento científico con respecto al conocimiento ordinario su objeto de reflexión. El representante más importante en esa dirección ha sido Gastón Bachelard, de quien Althusser toma el concepto en cuestión. Al respecto, puede consultarse: Pedro Karczmarczyk, "La ruptura epistemológica de Bachelard a Balibar y Pêcheux" en Estudios de epistemología (10), 9-33. Memoria Académica, 2013. Disponible en: http://www.memoria.fahce.unlp.edu.ar/art revistas/pr.7329/pr.7329.pdf

11 Louis Althusser, Althusser, La revolución teórica de Marx, México, Siglo XXI, 2011, 24.

12 Louis Althusser, op. cit., 75.

13 Ídem, 75.

14 Ídem, 133.

15 Ídem, 136.

16 Alain Badiou, op. cit., 21.

${ }^{17}$ El catálogo de prácticas sugeridas por Althusser varía, siendo invariantes la práctica económica, la política, la ideológica y la científica. La lista incorpora y tematiza un mayor número de prácticas en los años setenta. De todos modos, no se trata de catálogos exhaustivos sino de la insistencia en la indicación de que la práctica no coincide con un principio simple.
} 
En este sentido, resulta al menos llamativo que Althusser desarrolle una extensa argumentación orientada a detallar la estructura, no de la práctica en general o de prácticas singulares, sino de una práctica específica: la práctica teórica. Lo primero que hay que tener en cuenta en lo que respecta a la práctica teórica es que el término 'teoría' requiere una desambiguación. Por un lado, el uso del término 'teoría' y la referencia a la práctica teórica se encuentran asociados a las múltiples prácticas teóricas existentes. En segundo lugar, Althusser reserva el término 'Teoría de la práctica teórica' o 'Teoría' -con mayúsculapara la dialéctica materialista, a la que define como la "teoría de la práctica en general". ${ }^{18 U}$ na vez asociada la 'Teoría' a la dialéctica marxista, Althusser puede afirmar que existen múltiples campos en los que "no existe verdaderamente una práctica teórica marxista". En otras palabras, dado que es posible reconstruir la estructura de la dialéctica materialista a partir de la práctica teórica, existen una heterogeneidad de espacios o ámbitos distintos de la práctica teórica, que necesitan de la intervención de la dialéctica materialista y de la elaboración de su 'Teoría'.

Para evaluar el impacto de este gesto en el concepto de práctica, veamos las determinaciones que adquiere la estructura de la 'Teoría', acerca de la que Althusser provee algunas indicaciones generales. Una vez identificada con la dialéctica materialista, la 'Teoría' es definida como un proceso que involucra tres tipos de generalidades en la producción de conocimiento. Más precisamente, la 'Teoría' supone un trabajo de la llamada "teoría" (Generalidad II) sobre conceptos generales o abstracciones (Generalidad I) para transformar dichas abstracciones en conceptos específicos; es decir, para producir conocimiento (Generalidad III). Debe destacarse que en la 'Teoría' el movimiento de la dialéctica coincide con el de la producción de conocimiento científico. La segunda, es que tal y como está cifrado en La Revolución Teórica de Marx, el conocimiento consiste en el resultado de un proceso en cual un conjunto de abstracciones (Generalidad I) devienen conceptos específicos, científicos (Generalidad III). Finalmente, debe registrarse que en todo el proceso es jerarquizado, por sobre la materia prima y el producto, el momento de trabajo de transformación como determinante en la producción de conocimiento. De ahí que la Generalidad II - entendida como la unidad contradictoria de conceptos que constituye el campo en el que todo problema puede ser planteado en una ciencia - mantenga primacía con respecto a la Generalidad III y I. ${ }^{19} \mathrm{Si}$ bien Althusser ofrece tan solo estas indicaciones generales con respecto al proceso descrito, son suficientes para los fines que aquí interesan: destacar el proceso de transformación y la forma singular que adquiere el esquema productivo de las prácticas en el contexto de la práctica teórica.

No debe dejar de advertirse que el proceso de transformación descrito en la dialéctica materialista o 'Teoría' no se enfrenta como puro movimiento a una posible detención o estancamiento en un espacio que podría considerarse como la teoría 'pura', sino que resulta inmanente a la 'Teoría', de manera tal que teoría y práctica no se plantean como dos ámbitos escindidos. Tampoco se trata de un proceso de transformación unitario en la práctica. La dialéctica materialista es el correlato de un concepto de práctica social que no resulta en una unidad simple. Por el contrario, la práctica social es una unidad compleja que resulta imposible reducir a la categoría de simplicidad: "La 'práctica social', la unidad compleja de las prácticas que existen en una sociedad determinada contiene en sí un número elevado de prácticas distintas". ${ }^{20}$ Como indicaremos en el apartado siguiente, esta tesis es desarrollada en profundidad en el contex to de Para leer el capital.

Althusser da un paso más con respecto a la estructura de la 'Teoría de la práctica teórica' al establecer que, en un mapa general, el conjunto de las prácticas lleva adelante un procedimiento que responde a la misma estructura de la 'Teoría'. Se trata de la extrapolación de la manera en la cual la práctica teórica se encuentra organizada al conjunto de las prácticas sociales: "El problema de la relación

18 Louis Althusser, op cit., 138.

19 Ídem, 136.

20 Ídem, 136. 
de la teoría con su práctica, interesa a la Teoría general misma (la dialéctica) ya que en ella se expresa teóricamente la esencia de la práctica teórica en general y, a través de ella, la esencia de las transformaciones, de la "evolución" de las cosas en general". ${ }^{21}$ Con esta orientación, la "Teoría de la práctica teórica', lejos de ser un "método" aplicable a ámbitos heterogéneos, es el nombre de la estructura que permite pensar la manera en que se introducen transformaciones en las "cosas en general"; es decir, en la práctica en general.

En síntesis: la estructura de la "Teoría de la práctica teórica" permite dar cuenta de las transformaciones en el conjunto de las prácticas. Su estructura es la de la dialéctica materialista, cuya especificidad es asumida a partir de su diferencia con la génesis del concepto en la dialéctica hegeliana; esto es, a partir de la discontinuidad cualitativa que es introducida en la dialéctica en el proceso de producción. Así, Althusser otorga un estatuto contradictorio a la práctica: elabora una definición de práctica que destaca su carácter productivo a la vez que procura presenta una teoría de la práctica general cuya piedra angular consiste en el movimiento de transformación. Sin embargo, define a la estructura de la práctica general en base a la 'Teoría de la práctica teórica', en la cual el concepto de corte epistemológico resulta fundamental. De este modo, inscribe en la práctica a la dialéctica materialista, pero se trata de una dialéctica con una marca especulativa, acotada a la producción de conocimiento. Buena parte de las críticas al Althusser "teoricista" de los años sesenta se dirigen precisamente a este punto crítico en la fórmula de la 'Teoría de la práctica teórica': la extensión del modo en el cual la práctica teórica se encuentra organizada al concepto de práctica general, y con ella, a prácticas no-teóricas. En este sentido, si bien el carácter transformador de la práctica no se opone a una teoría que podría suponerse estanca, la transformación que tiene lugar en la práctica general coincide con la operación del corte, cuyo carácter especulativo -al menos en principio- resulta evidente.

\section{Primacía de la práctica: el todo social complejo es sede de las prácticas}

Como hemos anticipado, en La revolución teórica de Marx la práctica es concebida en su diferencia con la categoría de simpleza y no admite su oposición a una 'teoría'. Para leer el capital profundiza este gesto al sugerir el abandono de un concepto general de práctica hacia la presentación de una multiplicidad de prácticas inscriptas en un todo social:

Hay que reconocer que no existe práctica en general, sino prácticas distintas que no están en una relación maniquea con una teoría que les sería totalmente opuesta y extraña. Porque no existe por un lado la teoría - que no sería sino pura visión intelectual sin cuerpo ni materialidad - y, por el otro, la práctica totalmente material que se "pondría manos a la obra (...).

Nosotros afirmamos teóricamente la primacía de la práctica mostrando que todos los niveles de la existencia social son los lugares de distintas prácticas: la práctica económica, la práctica política, la práctica ideológica, la práctica técnica y la práctica científica (o teórica). Nosotros pensamos el contenido de estas diferentes prácticas pensando en su estructura propia que es, en todos casos, la estructura de una producción: concibiendo lo que distingue entre sí a estas estructuras, es decir, la naturaleza diferente del objeto al cual se aplican, de sus medios de producción y de las relaciones en que producen. ${ }^{22}$

\footnotetext{
21 Ídem, 138.

${ }^{22}$ Louis Althusser, op. cit., 65.
} 
De este modo, una multiplicidad de prácticas pertenecientes a un todo social complejo estructurado queda vinculada a la afirmación del principio de la primacía de la práctica. ${ }^{23}$ Lo novedoso en este movimiento es que explicita el rechazo a la problemática filosófica que organiza a teoría y práctica como un par de contrarios: la problemática de la escisión hegeliana. Dicha problemática identifica todo lo que puede ser designado como práctica. En otras palabras, pueden -o no- nombrarse aspectos diferenciados de la práctica, pero estos mantendrán siempre, y a pesar su aparente separación, una continuidad de esencia. Althusser llama concepción igualitarista de la práctica a la concepción solidaria con la problemática de la escisión ${ }^{24}$ : aquella concepción que iguala todo aquello que es designado con el nombre de práctica. En el marco del proyecto althusseriano, se trata de defender el principio de la primacía de la práctica de las lecturas que adscriben a un principio simple y homogeneizador.

Como hemos indicado, Althusser discute la asignación de la práctica a una categoría de simplicidad y asigna a múltiples prácticas lugares en un todo social estructurado. En este sentido, adquiere relevancia determinar algunas implicancias de la asociación de la práctica con una estructura y las notas que definen dicha totalidad. En la determinación del concepto de todo social marxista, Althusser encuentra necesaria una delimitación con respecto a la totalidad hegeliana para elaborar un concepto del todo social coherente con la ruptura epistemológica introducida por Marx. Para leer el Capital ofrece una exhaustiva caracterización del todo social marxista en "Los defectos de la Economía Clásica. Bosquejo del concepto de tiempo histórico". ${ }^{25}$ Allí Althusser analiza el concepto hegeliano del tiempo histórico como un contraejemplo pertinente para visualizar cómo funda Marx la temporalidad del todo marxista con respecto a la temporalidad en la totalidad hegeliana. Una delimitación con respecto a temporalidad hegeliana permite elucidar de qué manera el conjunto de las prácticas se inscriben en la temporalidad del todo social marxista estructurado.

Dos características fundamentales definen a la temporalidad hegeliana. La primera es la continuidad homogénea del tiempo. Ella remite a la continuidad del tiempo como reflejo del desarrollo dialéctico y a la consecuente dificultad de periodizar las sucesiones de una totalidad dialéctica con respecto a otra. La segunda característica consiste en la contemporaneidad del tiempo histórico. Esta característica captura un aspecto del tiempo histórico hegeliano en el que resulta oportuno detenerse: que el tiempo histórico sea contemporáneo indica que todos los elementos de la totalidad coexisten en un mismo presente, siendo siempre contemporáneos entre sí. La imagen de totalidad que dicha temporalidad arroja es la de una unidad espiritual que garantiza que cualquier parte sea expresión de la totalidad como tal. En el todo espiritual es posible realizar un corte de esencia en la totalidad y dar con sus determinaciones positivas. Las determinaciones de la totalidad -entiéndase, determinadas formas políticas, ideológicas, económicas o filosóficas- se encuentran fundadas en y expresan a la totalidad. ${ }^{26}$

A la concepción del 'todo espiritual', Althusser opone el concepto marxista del todo social como todo social estructurado. Debe insistirse en la ruptura con el concepto de 'todo espiritual' porque en Marx no se encuentra la base que daba a la totalidad hegeliana su unidad. En efecto, se trata de un todo que mantiene una unidad compleja - en oposición a la unidad espiritual del todo hegeliano-. En este sentido, implica una serie de instancias o niveles relativamente autónomos ${ }^{27}$.

Hasta aquí, en el todo social estructurado, los "niveles" no son otra cosa que el nombre de las múltiples prácticas, que se organizan a partir de un principio que establece su dependencia a un todo social a la vez que les otorga relativa autonomía. A lo que debe agregarse un paso más: la existencia de

\footnotetext{
23 Para los fines que ocupan a esta investigación nos referiremos a las prácticas, a las instancias y a los niveles del todo social estructurado de manera indistinta.

24 Ídem, 6.

25 Ídem, 101.

26 Ídem, 104.

27 Ídem, 104-106.
} 
instancias que guardan relativa independencia entre sí habilita la construcción del concepto de la de su temporalidad histórica específica:

\begin{abstract}
Éste es el principio que fundamenta la posibilidad y la necesidad de historias diferentes correspondientes respectivamente a cada uno de los "niveles". Este principio es el que nos autoriza a hablar de una historia económica, de una historia política, de una historia de las religiones, de una historia de las ideologías, de una historia de la filosofía, de una historia del arte, de una historia de las ciencias, sin jamás eximirnos sino, por el contrario, imponiéndonos el pensar de la independencia relativa de cada una de estas historias es la dependencia específica que articula, los unos con los otros, los diferentes niveles en el todo social. ${ }^{28}$
\end{abstract}

Así, y contra la evidencia de que cada práctica resulta accesible de manera "pura", descubrir los ritmos y el tipo de articulación entre los tiempos de los niveles requiere, también, de la elaboración de su concepto. En este sentido, y dadas las características de la categoría de totalidad en Marx; es decir, dado que cada práctica ya no está subordinada a una temporalidad homogénea, la identificación de las prácticas con niveles indica la necesidad de la construcción del concepto de su temporalidad propia. Dicho de otro modo, el todo social marxista, habilita la construcción del concepto del tiempo histórico de la práctica ideológica; así como el concepto del tiempo histórico de la práctica política, el de la práctica científica, etc. Un ejemplo que permite considerar el alcance y la relevancia de dicha operación: la filosofía. Determinar el concepto del tiempo histórico filosófico requiere de la consideración de la filosofía como perteneciente a la práctica teórica en su articulación con múltiples prácticas teóricas. También requiere de la definición de la relación de la filosofía con otras prácticas sociales. ${ }^{29}$ De este modo, construye la realidad que constituye a las formaciones filosóficas.

En cierta medida, hasta aquí solo se han desplegado las consecuencias del enunciado según el cual la práctica constituye una unidad compleja. Dicho de otro modo, el concepto general de práctica es el de una multiplicidad de prácticas organizadas en un todo social estructurado ${ }^{30}$. Étienne Balibar repara en esta observación cuando, en el prólogo escrito en 2010 a la reedición francesa de La Revolución teórica de Marx, establece que estructurar y ordenar el conjunto de las prácticas es volver inteligible la manera en que las diferentes prácticas se relacionan en el todo social. ${ }^{31}$ Esto es, el concepto de su temporalidad específica y el tipo de dependencia que mantienen en el todo social.

\title{
Las prácticas en un todo jerarquizado
}

Hemos indicado que el concepto de la temporalidad específica de las prácticas debe inscribirse en la dependencia que estas guardan con respecto al todo social. Queda aún precisar el tipo de organización que supone el todo social estructurado, y con esto, el tipo de dependencia y de eficacia que sus niveles adquieren. Althusser plantea que la distribución de las instancias o niveles se presenta en el todo social organizado como un todo orgánico jerarquizado. ${ }^{32}$ Esto puede plantearse del siguiente modo: si

\footnotetext{
28 Ídem, 111.

29 Ídem, 112.

30 Deben introducirse aquí algunas aclaraciones con respecto a la identificación práctica-estructura. En primer término, resulta oportuno abandonar las aproximaciones rápidas que ofrecen una imagen de la estructura como algo fijo y contrapuesto a la práctica como actividad: la recurrencia a la estructura implica que toda práctica es el producto de una relación de combinación entre elementos y no el movimiento unitario de un agente. Esto no desestima la tensión entre la posibilidad de la transformación social y el rechazo del hombre como agente de la historia. Como habrá ocasión de señalar, la relación entre el par prácticaestructura y la acción política puede elucidarse partir del concepto de historia que el todo social marxista supone.

31 Louis Althusser, Pour Marx, Francia, La découverte, 2010, 8.

32 Louis Althusser, Para leer El Capital, México, Siglo XXI, 2015, 108-115.
} 
la totalidad hegeliana es una totalidad simple y sus determinaciones son expresión de una misma esencia, el todo social marxista se presenta como una articulación compleja de diferencias sometidas a una estructura dominante.

La 'dominancia' de una estructura sobre las demás es asociada al principio de la determinación en última instancia por la economía. Este principio establece una estructura dominante que organiza de una manera específica la articulación de los demás niveles, permitiendo de este modo "escapar al relativismo de los desplazamientos observables". ${ }^{33}$ En una primera aproximación, esto podría sugerir que debemos buscar a la práctica 'determinante' en la práctica productiva. Veamos esto más de cerca. En un sentido descriptivo, la tesis de la determinación en última instancia por la economía se basa la metáfora tópica que organiza el todo social en una superestructura jurídico-política y una infraestructura económica para luego establecer una jerarquía de la segunda sobre la primera. Se trata de una cuestión espinosa y largamente debatida, y si bien no resulta posible ni necesario otorgar alguna respuesta para los fines que nos ocupan aquí, interesa establecer algunas precisiones con respecto a los términos en los que Althusser entiende que la metáfora tópica debe ser planteada para aproximarse a la definición de 'lo económico' la práctica productiva- y a su eficacia propia con respecto a las prácticas sociales.

En primera instancia, no se trata de una reformulación sin más de la escisión entre superestructura jurídico-política e infraestructura económica. Al lidiar con la metáfora tópica, se ingresa nuevamente al problema de la inversión de la dialéctica hegeliana. En particular, Althusser señala de manera insistente que la fundación de la dialéctica materialista supone una transformación en los términos mismos involucrados en la concepción de la sociedad de Hegel. La concepción hegeliana de la sociedad parte de la existencia de dos esferas: la sociedad civil y la sociedad política; identificadas, la primera, con el ámbito económico -el reino de la necesidad-, y la segunda, con el Estado -como realidad de la Idea-34 Pero como hemos sugerido, Althusser encuentra en Marx una transformación de la naturaleza misma de la dialéctica; y con ella, los términos involucrados en las dicotomías que esta presenta. En este sentido, la tesis de la determinación en última instancia por la economía no acepta acríticamente la categoría de sociedad civil ni la de sociedad política presente en Hegel. Por el contrario, supone una distancia con identificación de la economía con un 'reino de la necesidad' y con la aceptación del Estado como 'realidad de la idea'.

En una orientación similar, Althusser establece que una definición de 'lo económico' en Marx debe reparar en que cuando Marx realiza una crítica a la economía política pone en marcha una crítica al objeto de la economía política. ${ }^{35} \mathrm{El}$ objeto de la economía política - "los hechos económicos"- tiene dos características fundamentales que son sometidas a discusión: el primero es el supuesto de que los fenómenos económicos se presentan como ya 'dados' - accesibles a observación directa- en un terreno homogéneo. El segundo de ellos es la postulación del homo economicus como causa de los hechos económicos. En otras palabras, la aceptación de una relación intrínseca entre fenómenos o hechos económicos con necesidades "humanas", cuya satisfacción requiere de la díada consumo-producción. ${ }^{36}$ Con respecto al segundo aspecto del objeto de la economía política, Althusser recupera la crítica de Marx que señala el carácter histórico de las necesidades humanas y su dependencia del desarrollo de las fuerzas productivas, por un lado, y de los salarios y las formas de repartición de plusvalía, por el otro. ${ }^{37}$ De este modo, rechaza al marxismo como una filosofía que hace del trabajo un punto de origen, reformulando el objeto del materialismo histórico a partir de una redefinición de la categoría de producción. La definición de 'lo económico' en Marx debe partir de una delimitación con el objeto de la economía política clásica. Aquí

33 Louis Althusser, op. cit., 109.

34 Louis Althusser, La revolución teórica de Marx, México, Siglo XXI, 2011, 169, 87-89.

35 Louis Althusser, Para leer El Capital, México, Siglo XXI, 2015, 119.

36 Aquí es preciso aclarar que Althusser considera que la "antropología ingenua" que la díada consumo-producción tiene a sus bases es por Hegel, quien identifica a la sociedad civil con el 'reino de la necesidad'. Cf. Louis Althusser, op. cit., 173- 175.

37 Ídem, 179. 
se pone en juego la crítica al concepto de 'lo económico' como un espacio homogéneo y plano, accesible a la observación inmediata.

¿Cuál es, entonces, la elaboración del concepto de ‘lo económico’ que Althusser registra en Marx? En primer lugar, al situar lo económico o práctica productiva en el todo social estructurado, Althusser sienta las bases para un nuevo concepto de producción que requiere de dos condiciones indisociables para su existencia: el proceso de trabajo, por un lado, y las relaciones de producción, por el otro. El proceso de trabajo reúne lo que Althusser denomina las condiciones técnicas y materiales de la producción. Resulta de la combinatoria de una fuerza de trabajo determinada, con un objeto (sobre el cual trabaja) y los medios de producción. Por otro lado, las relaciones de producción se definen en función de combinaciones específicas de los agentes del proceso de producción y las condiciones presentadas. En síntesis: la forma en la que la práctica productiva se organiza establece una definición de 'lo económico' como un espacio complejo.

Dada la presentación de la práctica económica como un espacio complejo, Althusser realiza la siguiente advertencia:

(...) si el campo de los fenómenos económicos ya no es este espacio plano, sino un espacio profundo y complejo, si a los fenómenos económicos que están determinados por su complejidad (es decir, su estructura) ya no se les puede aplicar, como antaño, el concepto de causalidad lineal, se precisa de otro concepto para dar cuenta de la nueva forma de causalidad requerida por la nueva definición del objeto de la economía política por su 'complejidad', es decir, por su determinación propia: la determinación por una estructura. ${ }^{38}$

Los fenómenos económicos se encuentran determinados por su estructura regional, determinada a su vez por la estructura global, de manera tal que una definición de una causalidad lineal basada en lo económico como un espacio homogéneo pierde todo espesor. Así, aparece el problema de la determinación de los elementos de una estructura y las relaciones estructurales, que ha de pensarse fuera de los esquemas clásicos de la causalidad (expresiva o mecánica). Más aún, debe pensarse cómo se presenta la determinación de los elementos del todo por la estructura del todo mismo. ${ }^{39}$ En otras palabras, debe precisarse el concepto de causalidad estructural.

Para evaluar el impacto de la causalidad estructural en el concepto de práctica es preciso realizar una breve recapitulación del recorrido trazado hasta aquí: en primer lugar, la inscripción de la práctica en la dialéctica materialista. En segunda instancia, la afirmación de la primacía de la práctica y la ubicación de una multiplicidad de prácticas en el todo social estructurado. A continuación, la necesidad de pensar la eficacia propia de las prácticas en tanto niveles de un todo social. Es en este punto, en donde la subordinación de las prácticas al todo social estructurado como todo jerarquizado implica el desarrollo de un principio que permita pensar la determinación de los elementos del todo por la estructura del todo.40 Como puede preverse, debe tratarse de un principio no lineal y no expresivo. En este sentido, la causalidad estructural no es otra cosa que el tipo de causalidad relativo al todo social marxista.

Althusser recurre a otro nombre para llamar a la causalidad estructural: el de sobredeterminación. En el contexto de Para leer el capital, este concepto intenta capturar de qué manera existe una estructura en sus elementos. Se remite, para la precisión del concepto de sobredeterminación, al concepto de causa inmanente desarrollado por Spinoza ${ }^{41}$. Si bien la filiación spinozista del concepto de sobredeterminación

38 Ídem, 199.

39 Ídem, 200.

40 Ídem, 202.

${ }^{41}$ Debe agregarse a la referencia a Spinoza que el concepto de sobredeterminación es recuperado por Althusser del psicoanálisis y de la lingüística estructural de inspiración saussureana. Freud produjo el concepto para capturar modo en el cual se relaciona 
es objeto de grandes debates, es importante explicitar el sentido general que adquiere: el concepto de causa inmanente pone de relieve la inmanencia de la estructura a sus efectos. ${ }^{42}$ En otras palabras, implica que toda estructura consiste en sus efectos y que no existe en modo alguno una causa exterior a ella. En La revolución teórica de Marx Althusser desarrolla el concepto de sobredeterminación como un rasgo de la contradicción de la dialéctica materialista. En este sentido, aparece en el marco de un análisis de la especificidad de la contradicción en la dialéctica materialista con respecto a la hegeliana. Althusser tematiza el concepto marxista de contradicción basándose en el tema del eslabón más débil de la cadena, desarrollado por Lenin. En líneas generales, la posición de Lenin muestra que no basta la contradicción entre las fuerzas de producción y las relaciones de producción para generar una situación revolucionaria: para que la contradicción pueda activarse, en preciso que se acumulen una serie de situaciones y que se fusionen en una unidad de ruptura. ${ }^{43} \mathrm{En}$ este sentido, sin hacer desaparecer sus diferencias y a partir de su propia consistencia, contradicciones de origen y niveles heterogéneos se fusionan en una unidad fundamental. La fusión de contradicciones de proveniencia heterogénea permite hablar de una contradicción sobredeterminada.

Aquí aparece un problema cuya elucidación excede a esta investigación, pero que resulta indispensable mostrar. La dificultad aparece, como buena parte de la literatura sobre el tema se ha ocupado de señalar al intentar compatibilizar el concepto de determinación en última instancia por la economía con el de sobredeterminación. ${ }^{44}$ La lectura que quisiéramos sugerir en lo que respecta al concepto de sobredeterminación, es que este se inserta en el marco de una concepción materialista de la contradicción. Seguimos en este sentido a Juan Domingo Sánchez Estop ${ }^{45}$, quien ha señalado que el concepto de sobredeterminación es aquello que habilita una teoría de la contradicción liberada de una ontología de la expresión hegeliana. Se trata de pensar una contradicción "que se manifiesta en una instancia del todo social, pero que desplaza otro tipo de contradicciones a la vez que las condensa convirtiéndose así en contradicción dominante, sin estar determinada por una contradicción "determinante". En este sentido, acerca de la determinación en última instancia debe enfatizarse la última instancia antes que la determinación, recuperando una formulación de Althusser según la cual la hora de la última instancia jamás llega a sonar. ${ }^{46}$

Hasta aquí, la presentación de un concepto de todo social que aloja la complejidad y la multiplicidad que un concepto no unitario de práctica supone. Dada la lectura que efectúa Althusser del principio de la primacía de la práctica, la afirmación de la existencia de múltiples prácticas es el correlato de la transformación que sufre la categoría del todo social en Marx, a partir de su delimitación de la totalidad hegeliana. Las prácticas quedan organizadas en un todo social jerarquizado. Ello supone una causalidad que repulsa la organización de las prácticas en la metáfora tópica tradicional y construye su

el contenido latente del sueño con su contenido manifiesto a partir de dos mecanismos: la condensación y el desplazamiento. Se trata de un problema largamente discutido, que probablemente no ha mostrado aún todas sus aristas y dimensiones. Con respecto a la referencia a Spinoza, puede consultarse "Sobredeterminación, complejidad, beatitud" de Gil Morejón, quien ha contribuido enormemente a fijar la relación entre el concepto de sobredeterminación y la ontología spinozista: Gil Morejón, "Overdetermination, Complication, Beatitude: Althusser's Physics of Social Modes," en Décalages: Vol. 2, Iss., 2, 2016. Disponible en : https://scholar.oxy.edu/decalages/vol2/iss2/11

42 Louis Althusser, op. cit. 204.

43 Louis Althusser, La revolución teórica de Marx, México, Siglo XXI, 2011, 77.

${ }^{44}$ Laclau y Mouffe defienden la idea según la cual el concepto de determinación en última instancia inhabilita el surgimiento del vínculo hegemónico al mantener un compromiso con temas y categorías de la ortodoxia determinista y economicista. Existiría una contradicción entre el concepto de determinación en última instancia y el de sobredeterminación en la medida en que el primero rechaza la categoría de articulación presente en el segundo, por tratarse de una necesidad ahistórica. Por el contrario, el concepto de sobredeterminación tendría lugar ahí donde es afirmada la apertura de lo social y la variación contingente. Ernesto Laclau y Chantal Mouffe, Hegemonía y estrategia socialista. Madrid, Siglo XXI, 1987, 165-170.

45 Juan Domingo Sánchez Estop, Ni estrategia ni socialismo. Una lectura althusseriana de Laclau, Registro del II Coloquio 'Althusser hoy: estrategia y materialismo, Santiago de Chile, 2017, 4.

${ }^{46}$ Louis Althusser, op. cit., 93. 
concepto en base a la eficacia que cada práctica adquiere en el conjunto. El concepto de sobredeterminación permite pensar la eficacia de las prácticas otorgando un tipo de causalidad específica al todo social marxista, esquivando una causalidad mecánica o expresiva.

\section{Lenin y la práctica política: hacia la lucha de clases}

Hacia finales de la década del sesenta y principios de los años setenta Althusser elabora una crítica de su producción teórica temprana, y más específicamente, de lo que se califica como una 'desviación teoricista' presente en La revolución teórica de Marx y Para leer el Capital. En este sentido se dirigen un conjunto de textos que detallan la relación necesaria entre la práctica y la lucha de clases. Así, la práctica política es destacada como un aspecto central y determinante de la filosofía es planteada de manera decisiva en Lenin y la filosofía ${ }^{47}$, una conferencia ofrecida en la Sociedad Francesa de Filosofía en febrero de 1968. En esas líneas, Althusser continúa la búsqueda de una definición de la dialéctica materialista profundizando en la experiencia de lucha revolucionaria, recogida de manera excepcional en el pensamiento de Lenin. El dirigente soviético muestra en qué consiste la ponderación de la práctica política en la toma de decisiones. En circunstancias precisas en las que la unidad de los bolcheviques se encontró amenazada, la jerarquización de la política resultó determinante sobre las discusiones teóricas. ${ }^{48}$

En este sentido, el nombre de Lenin invita a elaborar una teoría no filosófica de la filosofía; esto es, de una teoría que muestre el vínculo constitutivo de la filosofía con la práctica política. ${ }^{49}$ La filosofía se transforma en un terreno conflictivo, de manera tal que cobran relieve dos tendencias fundamentales cuyo conflicto y enfrentamiento ha sido una constante a lo largo de la historia de la filosofía-: una tendencia idealista y una materialista. Si la primera tendencia reniega del vínculo constitutivo entre filosofía y política, la segunda tiene como tarea central el 'trazado de líneas de demarcación' mediante el rechazo de las nociones ideológicas que representan al idealismo ${ }^{50}$, en particular, de la manera en la cual el idealismo se representa su vínculo con la política. El enfrentamiento entre tendencias es pensado a partir de la tesis de que la filosofía no tiene historia (en el sentido en el que las ciencias tienen historia) y que consiste ni más ni menos que en la repetición de este antagonismo:

Pero entonces hay que ir más lejos todavía y decir que si toda la historia de la filosofía no es más que machacar argumentos en los que se consuma una sola y única lucha, la filosofía es solo lucha de tendencias, esa Kampflatz de la que hablaba Kant, pero que nos lanza entonces en la subjetividad pura y simple de luchas ideológicas. ${ }^{51}$

Una diferencia debe advertirse aquí con respecto a la definición de la filosofía otorgada en los llamados textos 'clásicos'. Si la determinación de los mecanismos de la producción del efecto de conocimiento -y la elucidación de la estructura de la práctica teórica - constituía la tarea primordial de la filosofía al ser definida como 'Teoría de la práctica teórica'; la jerarquización de la práctica política implica que la filosofía sea considerada como una continuación de la política en otros términos y que resulte irreductible a una tarea de orden especulativo. En síntesis: la nueva práctica de la filosofía tiene como condición la elaboración de una teoría no filosófica de la filosofía, que muestre el vínculo entre la filosofía y la práctica política.

\footnotetext{
${ }^{47}$ Louis Althusser, Lenin y la filosofía, México. Ediciones Era. 1970.

48 Louis Althusser, op. cit., 23-24.

49 Ídem, 13.

50 Ídem, 68.

51 Ídem, 60.
} 
La definición de la filosofía otorgada en Lenin y la Filosofía resulta pertinente para la determinación del concepto general de práctica porque ella pone de manifiesto que el materialismo dialéctico cuenta ahora con un aspecto político que le resulta inexpugnable. De este modo, habilita una redefinición de la transformación que tiene lugar en las prácticas:

Resulta de ello que únicamente con Lenin puede por fin tomar cuero y sentido la frase profética de la Tesis XI sobre Feuerbach. (Hasta ahora) "Los filósofos no han hecho más que interpretar de diversos modos el mundo, pero de lo que se trata es de transformarlo.” ¿Promete esta frase una filosofía nueva? No lo creo. La filosofía no será suprimida: la filosofía seguirá siendo la filosofía. Pero sabiendo lo que es su práctica, y sabiendo lo que ella es, o empezando a saberlo, pude ser poco a poco transformada por aquella. ${ }^{52}$

Las Tesis sobre Feuerbach ponen nuevamente de relieve el problema de le relación entre la teoría y la práctica y la cuestión de la transformación. La figura de Lenin traduce lo que, desde su anuncio en las Tesis, constituye un imperativo hacia la práctica como solución a las desviaciones especulativas en el campo del marxismo. A su vez, el nombre de Lenin introduce una delimitación con respecto a la filosofía de la praxis; en todo caso, la apuesta es la de una práctica de la filosofía que tome posición y muestre su vinculación con la práctica política: "Lo que el marxismo introduce de nuevo en la filosofía, es una nueva práctica de la filosofía. El marxismo no es una (nueva filosofía de la praxis, sino una práctica (nueva) de la filosofía". ${ }^{53}$ La 'solución al misticismo' que las Tesis exigen requiere de la tematización de los conflictos políticos en la filosofía; cuestión que resulta, al menos en principio, irreductible a una reflexión epistemológica. En este sentido, la filosofía adquiere dimensiones tácticas y estratégicas y las tesis filosóficas se convierten en posiciones de alcance político. En la medida en que la práctica resulta indisociable de la dialéctica materialista, la definición positiva del carácter político de la práctica conmueve la estructura de los múltiples procesos que tienen lugar en el todo social estructurado. En otras palabras, la dialéctica materialista adquiere una determinación política que la aleja de la estructura de la práctica teórica -'Teoría de la práctica teórica’-

\section{Crítica a la 'Teoría de la práctica teórica': lucha de clases y Autocrítica}

El lugar otorgado por Althusser a la práctica política adquiere mayores precisiones a lo largo de la década del setenta. Esto es claro en Para una crítica de la práctica teórica: respuesta a John Lewis ${ }^{54}$, un artículo escrito y publicado en 1972 en Marxism Today, la revista del Partido Comunista británico. El ensayo responde a una serie de críticas que John Lewis, filósofo y militante del partido inglés, arroja en un artículo titulado El caso Althusser, publicado en la misma revista algunos meses antes. En este sentido, la Respuesta polemiza vehementemente con un conjunto tesis que son el fundamento de la crítica de John Lewis a Althusser. También escrito en 1972, Elementos de autocrítica55, mantiene una dirección similar a la Respuesta en su delimitación de la 'desviación teoricista' y en el señalamiento del olvido de la lucha de clases de los

\footnotetext{
52 Ídem, 38.

53 Ídem. La filosofía de la praxis tiende a asemejar la totalidad marxista con la totalidad hegeliana produciendo el aplanamiento de todas las prácticas sociales en la historia concebida como un desarrollo continuo y homogéneo. Retomando el lenguaje de las Tesis sobre Feuerbach, lo que podríamos llamar la actividad de la práctica consiste en su constitución como criterio o guía, en contraposición una teoría estanca. Como hemos indicado, Althusser contrapone a dicha escisión la definición de las prácticas en plural- en función de distintos tipos de trabajo de transformación de una materia prima dada en un producto determinado

${ }^{54}$ Louis Althusser, Para una crítica de la práctica teórica. Respuesta a John Lewis, Buenos Aires, Siglo XXI, 1974.

55 Louis Althusser, Elementos de autocrítica, España, Editorial Laia, 1975.
} 
textos clásicos. Althusser ocupa buena parte de sus esfuerzos en discutir la tesis según la cual el conjunto de las prácticas sociales replica la estructura de la 'Teoría de la práctica teórica'.

En la Respuesta, Althusser reconstruye las objeciones realizadas por John Lewis a partir de la enunciación de tres tesis. Nos detendremos en las dos primeras, en la medida en que permiten aproximarse a una cuestión nodal, ya presentada con motivo del concepto de tiempo histórico del todo social marxista: la relación entre el concepto de práctica y el de historia. La primera tesis que afirma John Lewis es que "el hombre hace la historia"; tesis que resulta complementada por una segunda, según la cual 'el hombre hace la historia trascendiendo la historia. Estas tesis ponen de relieve el problema del sujeto de la historia, Althusser presenta una advertencia con respecto a los términos implicados en la formulación de las tesis de John Lewis. ${ }^{56}$ Ellos esconden un mito del origen presente en el concepto de 'hombre', de manera tal que el 'hombre' sería el creador y recreador de aquello que trasciende en la historia. A propósito de esta categoría, es precisamente una delimitación con la categoría filosófica de 'hombre' lo que otorga un punto de partida del materialismo dialéctico.

En el límite, Althusser advierte que las tesis de John Lewis pretenden responder la siguiente pregunta: “¿Quién hace la historia?” En esta pregunta los términos suponen la existencia de un sujeto y a la historia como un resultado de su acción. En la medida que estos supuestos no sean aceptados, no debe presentarse sin más una respuesta a esta misma pregunta. Tras cuestionar que la figura del 'hombre' o de la 'suma de las voluntades de los hombres individuales', resultará que en todo caso son 'las masas' las que hacen las historia. Sin embargo, la historia, lejos de aparecer como el resultado de la acción de un sujeto, se presenta como el escenario de la repetición de la lucha de clases. Con esta afirmación desaparece el problema del sujeto de la historia, en la medida en que la historia aparece definida como un complejo sistema natural y humano cuyo motor es la lucha de clases. ${ }^{57}$

El impacto de la lucha de clases como motor de la historia en el concepto de práctica debe buscarse en la definición de la estructura del tiempo histórico de la totalidad marxista. En el todo social estructurado, es decir, en la multiplicidad de prácticas que éste aloja, las prácticas son definidas a partir de las categorías que constituyen el tiempo histórico. Así, las prácticas se transforman en el escenario de la lucha de clases. Es visible en qué medida la estrategia de Althusser mantiene una continuidad con el movimiento de Lenin y la filosofía, es decir, con una politización general de la filosofía y de las prácticas sociales. La filosofía ya no puede ser considerada en los mismos términos ni bajo el mismo esquema que la práctica teórica. La filosofía debe poner en consideración al conjunto de las prácticas sociales y las contradicciones - la lucha de clases - que las organizan. Hasta aquí, la nueva práctica de la filosofía que Althusser anuncia supone una transformación del concepto de práctica y una introducción de la lucha de clases como un elemento determinante.

\section{Una multiplicidad de prácticas: una posición marxista en filosofía}

La filosofía se encuentra ligada al conjunto de las prácticas, de manera tal que el modo que dicho vínculo adquiere determina las dos tendencias fundamentales en filosofía: una idealista y una materialista. Idealismo y materialismo no son los nombres de distintas filosofías enfrentadas en un campo filosófico ya determinado: el campo en el que se baten es su condición de existencia. El tipo de intervención que cada posición realiza recupera el vínculo entre la teoría y la práctica, o más bien, la afirmación de la primacía de uno de los términos del par sobre el otro.

\footnotetext{
56 Louis Althusser, Para una crítica de la práctica teórica. Respuesta a John Lewis, Buenos Aires, Siglo XXI, 1974, $23-24$.

57 Ídem, 75. En este marco, una aclaración se vuelve pertinente en lo que respecta a la cuestión de la acción política. Haber abandonado el problema del hombre como sujeto de la historia no se traduce en un rechazo del problema de la acción política. Más aún, este problema debe ser sometido a las condiciones de la lucha de clases.
} 
La posición idealista sostiene la tesis de la primacía de la teoría sobre la práctica. Al arrogarse la existencia de determinados 'objetos', la filosofía (idealista) -se pronuncia acerca de la práctica política, estética, científica, religiosa - pretende tener la última palabra sobre las prácticas. Establece con este gesto un dominio sobre ellas: las deforma. ${ }^{58}$ Así, la tendencia idealista invisibiliza su vínculo constitutivo con las prácticas que subordina. En efecto, la tendencia idealista se constituye como tal a partir del desplazamiento del espacio propio que poseen las prácticas sociales. En este sentido, la deformación que lleva adelante es doble: por un lado, somete a las prácticas a una "unidad no formal no contradictoria de un pensamiento que abarca a la totalidad"59; por el otro, establece entre ellas una jerarquía cuyo punto de partida no es otro que la deformación de sus elementos. Si la tendencia idealista en filosofía asume la enunciación de la verdad y organiza su exposición bajo la forma de un sistema que procura otorgarle un sentido al todo de los seres, no lo hace por razones técnicas, sino políticas. La filosofía idealista cumple con respecto a la práctica ideológica un rol fundamental: contribuye a la unificación de las ideologías en una ideología dominante. ${ }^{60}$ En otras palabras, opera destacando o reteniendo los elementos que resultan significativos con un propósito político. Sobre este aspecto discurre La transformación de la filosofía, conferencia dictada en 1976. Dos textos póstumos escritos durante ese mismo año; Ser Marxista en Filosofía ${ }^{61}$ y la Iniciación a la filosofía para no filósofos ${ }^{62}$ también definen la tendencia idealista en filosofía en función del gesto que afirma el principio de la primacía de la teoría sobre la práctica, es decir, la explotación por parte de la filosofía del conjunto de las prácticas sociales.

Como es de esperarse, la posibilidad de una posición marxista —o materialista — parte de una delimitación con la deformación de las prácticas que la tendencia idealista en filosofía impulsa:

La irrupción de la práctica es la denuncia de la filosofía producida como tal filosofía. Es decir, contra la pretensión de la filosofía de abarcar el conjunto de las prácticas sociales (y las ideas), de ver el «todo», como decía Platón, para establecer su dominio sobre estas mismas prácticas; contra la pretensión de la filosofía de no tener «un espacio exterior», el marxismo afirma que ciertamente la filosofía tiene «un exterior 》 o por decirlo con mejores palabras: que la filosofía no existe más que por ese 《exterior》 y para él. Este exterior (que la filosofía quiere hacerse la ilusión de someterlo a la Verdad) es la práctica, las prácticas sociales. ${ }^{63}$

Definida por la primacía de la práctica sobre la teoría, la tendencia materialista se vuelve "de entero a la práctica" hacia la liberación de las prácticas de la explotación de la filosofía; o de una filosofía que adjudica una verdad filosófica a las prácticas. ${ }^{64} \mathrm{La}$ tendencia materialista procura no subordinar a las prácticas de la elaboración de un sistema. En este sentido, se distingue de una filosofía de (la praxis, del arte, de la política). Una posición marxista en filosofía reconoce a las prácticas sociales como el afuera constitutivo de la filosofía. Es decir, las prácticas empujan a la filosofía a reconocer que tiene un exterior no filosófico, un afuera que la constituye como tal. En este sentido, las prácticas no son el 'objeto' de la filosofía ni necesitan de la filosofía para adquirir su verdad. Se constituyen en procesos de transformación

\footnotetext{
58 Un caso significativo de explotación de las prácticas por parte de la filosofía es la subordinación de las ciencias en definiciones de la filosofía como la "ciencia de las ciencias". En ella, la filosofía se sitúa "por encima" de las ciencias. Vale esta observación para la práctica política, cuyo objeto de transformación son las relaciones sociales: la 'filosofía política' tiende a asumir que la política es su objeto y que puede transformar las relaciones sociales desde un 'interior' filosófico.

${ }^{59}$ Louis Althusser, "La transformación de la filosofía” en Filosofia y lucha de clases, México, Distribuciones hispánicas, $1986,9$.

${ }^{60}$ Louis Althusser, op. cit., 13.

${ }^{61}$ Louis Althusser, Ser marxista en filosofía, Buenos Aires, Akal, 2015.

${ }^{62}$ Louis Althusser, Iniciación a la filosofía para no filósofos, Buenos Aires, Paidós 2014.

${ }^{63}$ Louis Althusser, "La transformación de la filosofía" en Filosofia y lucha de clases, México, Distribuciones hispánicas, $1986,4$.

${ }^{64}$ Louis Althusser, Iniciación a la filosofía para no filósofos, Buenos Aires, Paidós 2014, 232.
} 
que producen verdades ${ }^{65}$ en un proceso sin sujeto ni fin. Finalmente, una posición materialista en filosofía afirma que aquello que se encuentra en juego en el campo de batalla filosófico se encuentra fuera del campo. ${ }^{66}$ Es decir, que la lucha de clases en las sociedades de clase es aquello que constituye el campo de batalla filosófico. La nueva práctica de la filosofía anunciada por la figura de Lenin es la que admite el tipo de práctica que es la filosofía y la devuelve de entero a su exterior constitutivo que la tendencia idealista niega sistemáticamente.

\section{Conclusiones}

El concepto de práctica constituye un concepto articulador de la posición teórica de Althusser y marca la manera singular en el que el filósofo argelino efectúa una lectura de las Tesis sobre Fenerbach. Siguiendo a Marx, el rasgo fundamental atribuido a la práctica es su carácter transformador: el proceso de transformación de una materia prima dada en un producto determinado. Durante los años sesenta, Althusser presenta el concepto de 'Teoría de la práctica teórica' a partir del cual define la estructura "del conjunto de las prácticas". Hemos indicado que la 'Teoría de la práctica teórica' mantiene la estructura de la producción de conocimiento, de manera tal que replica el esquema del 'corte epistemológico'. En este contex to, Althusser define a la 'Teoría de la práctica teórica' como la dialéctica materialista y extiende con este gesto la estructura de la práctica teórica a la de las prácticas en general. En este sentido, si bien durante sus textos clásicos Althusser elabora una definición de la práctica que rompe con la escisión entre la teoría y la práctica y pone en escena el carácter complejo de la práctica; el concepto de práctica mantiene un carácter ambiguo: mantiene un carácter productivo a la vez que replica la estructura de la 'Teoría de la práctica teórica', es decir, una estructura especulativa. Para leer el capital despliega las consecuencias del enunciado según el cual la práctica constituye una unidad compleja, de manera tal que el concepto general de práctica se abre hacia una multiplicidad de prácticas. Las prácticas sociales se alojan en un todo social estructurado que es definido en función de su diferencia específica con la totalidad hegeliana: un todo social jerarquizado que mantiene una causalidad propia que no se identifica con la causalidad lineal de la metáfora tópica tradicional. En este contexto, el concepto de sobredeterminación es el que permite pensar la eficacia que cada práctica adquiere, y el tipo de causalidad específica del todo social.

En los años setenta el concepto de práctica sufre las transformaciones que acompañan el movimiento de politización de la filosofía iniciado por Althusser en Lenin y la Filosofía, y que perfilan el abandono de la definición de la dialéctica materialista como 'Teoría de la práctica teórica'. Este gesto comienza con una jerarquización de la práctica política y de la lucha de clases en el seno de la filosofía. La dialéctica materialista adquiere así una determinación política que reniega de la marca especulativa presente en la 'Teoría de la práctica teórica'. Los llamados textos de 'autocrítica' continúan esta orientación, de manera tal que Althusser abandona la definición de la 'Teoría de la práctica teórica' para poner en consideración a la lucha de clases como el motor de la historia, es decir, de las prácticas. Así, en la filosofía, la nueva práctica de la filosofía es la que puede ver que la filosofía es un campo de batalla en el cual se han jugado dos tendencias fundamentales a lo largo de la historia: una idealista y una materialista. La primera contribuye a la unificación de la ideología dominante pretendiendo elaborar un discurso acerca de un presunto 'objeto', a partir de la explotación de las prácticas. En este sentido, dicha tendencia se ordenada a partir del principio que otorga primacía a la teoría sobre la práctica. El principio de la primacía de la práctica define a la tendencia materialista, que se vuelca de entero a las prácticas para aceptar que constituyen un afuera constitutivo de la filosofía. La práctica de la filosofía que impulsa una tendencia materialista es la que admite que en el campo filosófico se encuentran en disputa aspectos que exceden

${ }^{65}$ Louis Althusser, "La transformación de la filosofía” en Filosofía y lucha de clases, México, Distribuciones hispánicas, $1986,5$.

${ }^{66}$ Louis Althusser, Ser marxista en filosofía, Buenos Aires, Akal, 2015, 197. 
al campo como tal, es decir, que la lucha de clases que organiza al conjunto de las prácticas resulta determinante en la discusión filosófica.

\section{Bibliografía}

Louis Althusser, Elementos de autocrítica, España, Editorial Laia, 1975.

, Iniciación a la filosofía para no filósofos, Buenos Aires, Paidós 2014.

-----------, La revolución teórica de Marx, México, Siglo XXI, 2011.

------------, "La transformación de la filosofía" en Filosofía y lucha de clases, México, Distribuciones hispánicas, 1986.

-, Lenin y la filosofía, México. Ediciones Era. 1970.

-, Para leer El Capital, México, Siglo XXI, 2015.

--------, Pour Marx, Francia, La découverte, 2010.

-, Para una crítica de la práctica teórica. Respuesta a John Lewis, Buenos Aires, Siglo XXI, 1974.

-, Ser marxista en filosofia, Buenos Aires, Akal, 2015.

Alain Badiou, "El (re)comienzo del materialismo dialéctico" en Materialismo histórico y materialismo dialéctico, México, Ediciones Pasado y Presente Siglo XXI, 1979.

Étienne, Balibar, La filosofía de Marx, Buenos Aires, Ediciones Nueva visión, 2000.

Éwanjé-Épée, Felix Boggio y G.M. Goshgarian, "Filosofía y revolución. Althusser sin teoricismo: entrevista con G.M. Goshgarian" en Décalages: Vol. 2: Iss. 1. 2016. Disponible en: https://scholar.oxy.edu/decalages/vol2/iss2/11

Francois Matheron, "Louis Althusser o la impureza del concepto" trad. Starcenbaum M. En Demarcaciones. $\mathrm{N}^{\circ}$ 1. Disponible en: https://revistademarcaciones.cl/francois-matheron-louis-althusser-o-la-purezaimpura-del-concepto/. 2014.

Pedro Karczmarczyk, "La ruptura epistemológica de Bachelard a Balibar y Pêcheux" en Estudios de epistemología (10), 9-33. Memoria Académica, 2013. Disponible en: http://www.memoria.fahce.unlp.edu.ar/art revistas/pr.7329/pr.7329.pdf

Ernesto Laclau y Chantal Mouffe, Hegemonía y estrategia socialista, Madrid, Siglo XXI, 1987.

Gil Morejón, "Overdetermination, Complication, Beatitude: Althusser's Physics of Social Modes," en Décalages: Vol. 2: Iss., 2, 2016. Disponible en : https://scholar.oxy.edu/decalages/vol2/iss2/11

Juan Domingo Sánchez Estop, Ni estrategia ni socialismo. Una lectura althusseriana de Laclau, Registro del II Coloquio 'Althusser hoy: estrategia y materialismo, Santiago de Chile, 2017. 